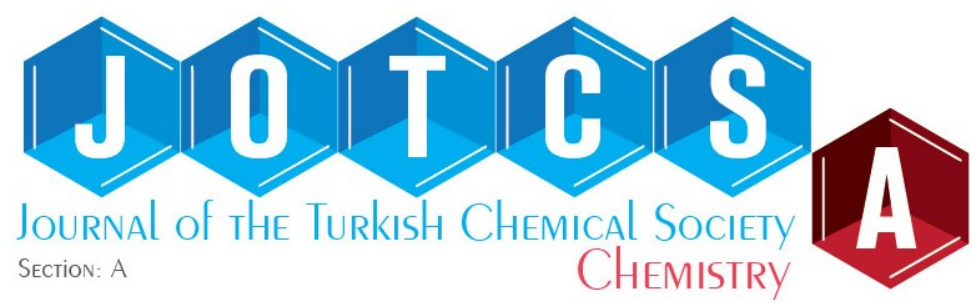

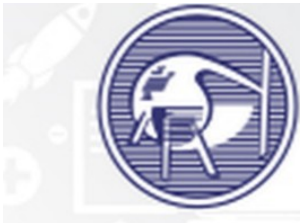

TURKISH

\title{
Investigation of Singlet Oxygen Production Property of Peripherally Tetra-substituted In(III)Cl Phthalocyanine for Photodynamic Therapy
}

\author{
Semih Gorduk* $\square$
}

Yildiz Technical University, Faculty of Arts and Science, Department of Chemistry, 34210 Istanbul, Turkey.

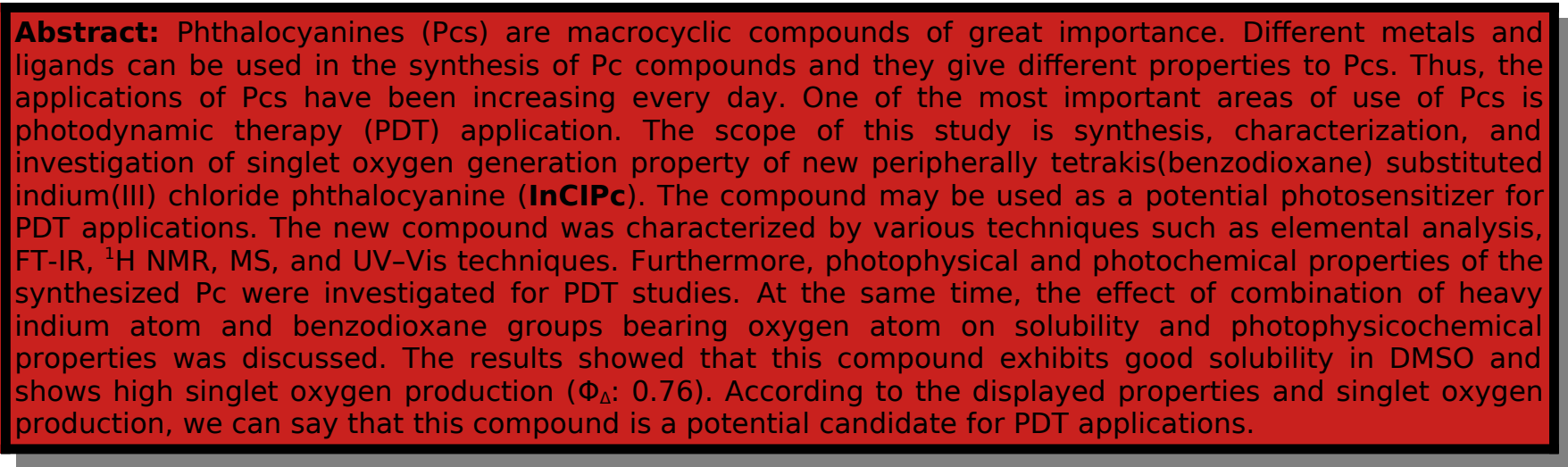

Keywords: Photodynamic therapy; phthalocyanine; singlet oxygen; indium(III) ion; photophysicochemical properties.

Submitted: October 19, 2020. Accepted: January 07, 2021.

Cite this: Gorduk S. Investigation of Singlet Oxygen Production Property of Peripherally Tetra-substituted In(III)Cl Phthalocyanine for Photodynamic Therapy. JOTCSA. 2021;8(1):279-88.

DOI: https://doi.org/10.18596/jotcsa.812081.

*Corresponding author. E-mail: sgorduk@yildiz.edu.tr, semih_grdk@hotmail.com

\section{INTRODUCTION}

Today, cancer is one of the most serious health problems. It is a disease that causes death of millions of people every year despite many completed and ongoing research and millions of people get this disease every year and unfortunately, most of them die (1). Many researchers and research institutions have been working intensively for the treatment of this disease (2). The disease occurs as a result of uncontrolled division and proliferation of cells and therefore it is gene-based. Since all living things have different gene structures, cancer is basically an individual disease (3). Therefore, it is not possible to talk about a single and definitive treatment method. Today, conventional methods such as surgical intervention, chemotherapy and radiotherapy are used $(4,5)$. As an alternative to these studies, photodynamic therapy (PDT) has become one of the important methods used in cancer treatment (6). It is important to design photosensitizers that will make PDT applications more effective (7, 8). Phthalocyanines (Pcs) are also used as a photosensitizing agent for this treatment method (911).

Pcs are of great importance both in application and science and there are many studies in the literature on Pc derivatives $(12,13)$. Pcs, which have physical and chemical properties that can be changed according to the purpose, are used in many application areas (13). The effective use of Pcs in 
Langmuir-Blodgett films, chemical sensors, nonlinear optical and electrode materials, electrochemistry, biomedical agents for imaging and PDT, and solar cell applications has led to increased interest in them (14-17). The properties that make Pcs attractive are their $\pi$-electron systems and their physical and chemical behavior. Pcs to be used for PDT applications have primarily high singlet oxygen production, displays selectivity for cancerous cells, show absorption in long wavelengths, prevent aggregation and should be soluble $(18,19)$. The major disadvantage of unsubstituted Pcs, which is insoluble in organic solvents, is overcome by the addition of various substituents to non-peripherally and peripherally positions of PC compounds. The solubility of Pcs can be increased by binding some functional groups (crown ethers, alkyl, alkoxy, carboxylate, alkylthio and the donor atoms such as $\mathrm{N}$ and $\mathrm{O}$ etc.) to peripherally position of $\mathrm{Pc}$ ring or by adding some metal ions ( $\mathrm{Zn}, \mathrm{Mg}$, In etc.) to the interior of Pcs (20-26). Therefore, in this study, benzodioxane ligand containing alkyl and oxygen atoms, which can increase the solubility of Pc compound, was chosen. Pc compounds containing benzodioxane ligand have been reported previously (27-32). Kantekin and co-workers also investigated the photophysical and photochemical properties including singlet oxygen quantum yield of the same $\mathrm{Pc}$ molecule bearing different metals ( $\mathrm{Zn}$ and $\mathrm{Mg}$ ) (31). However, indium(III) metal ion containing derivative of the same $\mathrm{Pc}$ has not been reported. Also, indium(III) Pcs show the potential to be used as a photosensitizer in PDT because of their ideal singlet oxygen quantum yield caused by the heavy atom effect of indium(III) atom $(33,34)$. Accordingly, indium(III) metal ion was chosen as the central atom in the ring of Pc compound.

Within the scope of this study, chloroindium(III) Pc compound, which can be used as a photo-sensitizing agent for PDT, containing benzodioxane groups was synthesized and its structure was characterized by various techniques. Herein, we aimed to increase the efficiency of the ideal photosensitizer by binding substituents containing oxygen atoms to Pc ring and to increase singlet oxygen production due to the heavy atom effect of indium(III) atom and thus absorption at long wavelengths was provided. These results have been supported with fluorescence, singlet oxygen production, photodegradation, and aggregation properties.

\section{EXPERIMENTAL SECTION}

\section{Materials and Equipments}

The used chemicals, equipments, materials, photochemical, and photophysical parameters and formulas were given in the supplementary information file.

\section{Synthesis of the Compound}

The 4-((2,3-dihydrobenzo[b][1,4]dioxin-2yl)methoxy)phthalonitrile compound used as a starting compound in this study was reported in our previous study (27). The new 2(3),9(10),16(17),23(24)-tetrakis- $\{(2,3-$

dihydrobenzo[b][1,4]dioxin-2-yl)methoxy)

phthalocyaninato chloroindium(III) (InCIPc) compound was synthesized for the first time according to given procedure in our previous works (27). As the only difference, anhydrous indium(III) chloride $(34.5 \mathrm{mg}, 0.156 \mathrm{mmol})$ for InCIPc were used in the synthesis. The detailed experimental procedure is given in supplementary information file.

2(3), 9(10), 16(17),23(24)-tetrakis- $\{(2,3-$ dihydrobenzo[b][1,4]dioxin-2-yl)methoxy)\} phthalociyaninato indium(III) chloride (InCIPc)

The THF: MeOH (100:6) solvent system was chosen for column chromatography. Yield: 35\% (59.18 mg), Mp: $>300{ }^{\circ} \mathrm{C}$, Anal. calc. for $\mathrm{C}_{68} \mathrm{H}_{48} \mathrm{ClInN}_{8} \mathrm{O}_{12}$ : C, 61.90; $\mathrm{H}, 3.67$; N, 8.49; Found: C, 61.70; $\mathrm{H}, 3.50 ; \mathrm{N}, 8.22 \%$. FT-IR (ATR, cm ${ }^{-1}$ ): 3045-3010 (Ar-CH), 2927-2875 (Aliphatic- $\left.\mathrm{CH}, \mathrm{CH}_{2}\right), 1622(\mathrm{C}=\mathrm{N}), 1587-1485(\mathrm{C}=\mathrm{C})$, 1250 (C-O-C). ${ }^{1} \mathrm{H}-\mathrm{NMR}\left(400 \mathrm{MHz}, \mathrm{CDCl}_{3}\right)$, ( $\left.\mathrm{C}: \mathrm{ppm}\right)$ : 7.76-7.65 (bm, 6H, Ar-H), 7.42-7.13 (bm, 6H, Ar-H), 6.93-6.40 (bm, 16H, Ar-H), 4.90 (bs, 4H, Aliphatic$\mathrm{CH})$, 4.51-4.13 (bm, $16 \mathrm{H}$, Aliphatic- $\left.\mathrm{CH}_{2}\right)$. UV-Vis (DMSO, $\left.1 \times 10^{-5} \mathrm{M}\right): \lambda_{\max } / \mathrm{nm}(\log \varepsilon): 709$ (4.80), 638 (3.78), 368 (4.40). MS (MALDI-TOF), (m/z): Calc.: 1318.216, Found: $1318.425\left[\mathrm{M}^{+}\right.$.

\section{RESULT AND DISCUSSION}

\section{Synthesis and characterization studies}

The synthesis procedure for the compound is presented in Scheme 1 . The synthesis and characterization studies of 4-((2,3-dihydrobenzo[b] $[1,4]$ dioxin-2-yl)methoxy)phthalonitrile compound used as a starting compound in this study were given in our previous work (27). On the other hand, InCIPc derivative in scope of this study was synthesized for the first time. We carried out nucleophilic substitution reactions between 2hydroxymethyl-1,4-benzodioxane and 4nitrophthalonitrile in order to obtain substituted phthalonitrile compound. InCIPc compound was obtained by cyclotetramerization of this compound in the presence of anhydrous indium(III) chloride and DBU as a catalyst. Purification of InCIPc was achieved by column chromatography (silica gel) with $\mathrm{THF} / \mathrm{MeOH}$ solvent mixture. The compound was obtained with 35\% yield and exhibited good solubility in DMSO. Various techniques such as FT-IR, elemental analysis, NMR, and MS were used to elucidate the structure of the compound.

In the FT-IR spectrum of InCIPc formed as a result of the cyclotetramerization of the phthalonitrile compound, the disappearance of the peak of the $\mathrm{C} \equiv \mathrm{N}$ group at $2230 \mathrm{~cm}^{-1}$ of the phthalonitrile and the 
formation of the $\mathrm{C}=\mathrm{N}$ group at $1622 \mathrm{~cm}^{-1}$ of $\mathrm{Pc}$ ring support the structure. In addition, vibrational bands of aromatic- $\mathrm{CH}\left(3045-3010 \mathrm{~cm}^{-1}\right)$, aliphatic- $\mathrm{CH},-\mathrm{CH}_{2}$ groups $\left(2927-2875 \mathrm{~cm}^{-1}\right)$ and $\mathrm{C}=\mathrm{C}\left(1587-1485 \mathrm{~cm}^{-1}\right)$ and C-O-C $\left(1250 \mathrm{~cm}^{-1}\right)$ bands of the Pc ring and substituted groups support the structure. The NMR spectrum of InCIPc compound is similar to the phthalonitrile derivative, which is the starting material. Due to the aggregation in Pc ring and deutero solvent, a broad spectrum was obtained according to the NMR spectrum of the phthalonitrile derivative. In the ${ }^{1} \mathrm{H}$ NMR spectrum, the signals of the aromatic protons were observed at around 7.76-
$6.40 \mathrm{ppm}$ and the signals of aliphatic protons were observed at around 4.90-4.13 ppm. These signals prove the formation of the expected structure. In the MALDI-TOF spectrum of the InCIPc compound, the

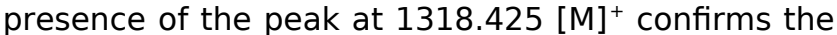
structure. The theoretical and experimental elemental analysis results are compatible with the targeted structure. The spectral data are compatible with the spectral data of previously published PC compounds $(27,30-32)$. It is seen that the data obtained from elemental analysis, FT-IR, mass, and ${ }^{1} \mathrm{H}$ NMR analyses of InCIPc compound are compatible with the synthesized structure.<smiles>CC#CCOCC1COc2ccccc2O1</smiles>

Scheme 1: General synthesis scheme for InCIPc (I: InCl $3, \mathrm{DBU}, \mathrm{n}$-pentanol, $\left.160{ }^{\circ} \mathrm{C}, 24 \mathrm{~h}\right)$.

\section{UV-Vis and Aggregation Studies}

Generally, UV-Vis spectroscopy is the most specific method used in the characterization of Pcs. PCS are highly colored compounds thanks to their $\pi$ electron system originating from benzene rings. This chromaticity causes them to give characteristic absorption bands in the visible and ultraviolet region. There are two characteristic bands in UV-Vis measurements of Pcs. The first of these is observed between $300-400 \mathrm{~nm}$. The band formed in this region is called as B-band or Soret band. The characteristic second band is observed around 600$750 \mathrm{~nm}$ and is called the Q band (35). The Q band is 
caused by $\pi-\pi^{*}$ transitions and therefore the absorption density is high. The shoulder in $\mathrm{Q}$ band gives information about whether $\mathrm{Pc}$ is metal or metal-free. Namely, while the only band observed in $\mathrm{Q}$ band indicates that the structure is a metallo Pc, the presence of two bands approximately equal to each other indicates that the structure is a metalfree Pc (36). At the same time, UV-Vis measurements help us to understand whether Pc is aggregated in the solvent from which the spectrum was taken. There are many factors that affect the absorption properties of Pcs. These can be listed as the substituents attached to Pc, the central metal atom, the position of the substituents, the solvent used to dissolve $\mathrm{Pc}$, the aggregation, the conjugation and the symmetry of molecule. When looking the presence of these two bands in the UVVis spectrum of the obtained compound, it is seen that InCIPc is formed (Figure 1). When the UV-Vis spectrum of the compound was examined, Q band at $709 \mathrm{~nm}$ and $B$ band at $368 \mathrm{~nm}$ were observed. No aggregation was observed in the UV-Vis spectrum of the compound taken in DMSO. The $\mathrm{Q}$ band of this compound appears to have shifted to red in the wavelength when compared to other peripherally tetra substituted Pcs containing benzodioxane (27). The important factor in the red shift of the $\mathrm{Q}$ band is due to the used heavy indium metal which binds the chlorine atom in the axial position in Pc ring. The red shift of $Q$ band has significant effects on photochemical and photophysical properties.

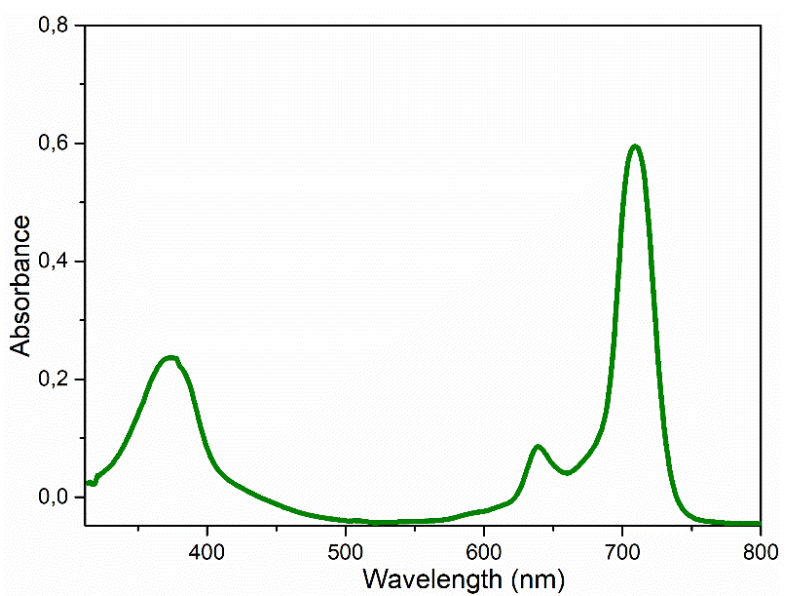

Figure 1: Electronic absorption spectrum of InCIPc in DMSO (Concentration: $1.0 \times 10^{-5} \mathrm{M}$ )

Aggregation is a problem in PDT. Aggregation is not a desirable situation in the application areas of PCS, as it causes widening and low resolution in the $\mathrm{Q}$ band seen in the UV-Vis spectrum of Pcs (37). The UV-Vis spectra of the compound in different concentrations $\left(2.00 \times 10^{-6}-1.20 \times 10^{-5} \mathrm{~mol} / \mathrm{L}\right)$ of DMSO are given in Figure 2. When the UV-Vis spectrum of the compound was examined, it was observed that the synthesized compound did not show aggregation in DMSO. In addition, it is seen that the molar concentration and the absorption intensity of the $\mathrm{Q}$ band change in direct proportion. This result is in accordance with the Lambert-Beer's Law.

Photophysical and photochemical Properties

The photochemical and photophysical properties of the compound in DMSO were investigated to determine whether it is suitable for PDT using UV-Vis and fluorescence spectrophotometers. Photochemical measurements include photodegradation quantum yield $\left(\Phi_{d}\right)$ and singlet oxygen quantum yield $\left(\Phi_{\Delta}\right)$, while photophysical measurements include fluorescence quantum yield $\left(\Phi_{\mathrm{F}}\right)$ and spectra.

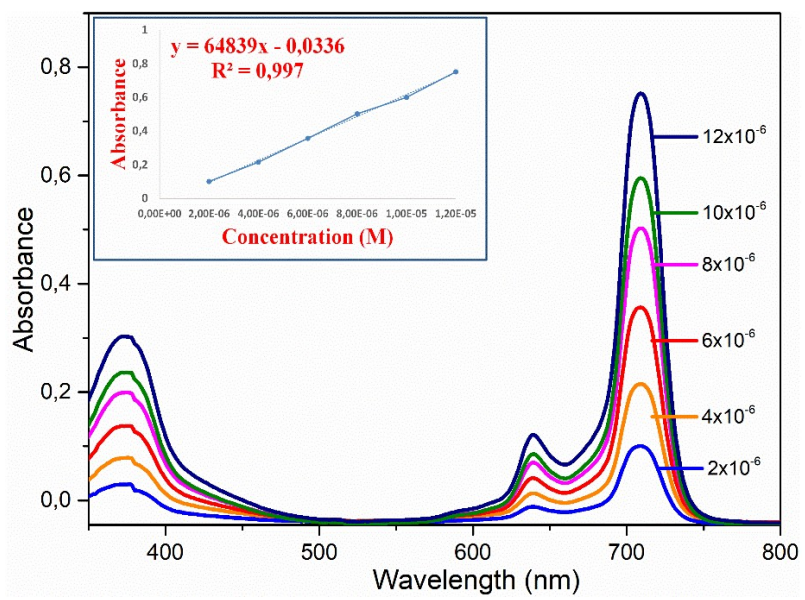

Figure 2: UV-Vis spectra of InCIPc compound in DMSO and at different concentrations for aggregation properties (Inset: Absorbances versus concentrations)

Fluorescence spectra and quantum yield $\left(\Phi_{F}\right)$ properties

The absorbance, emission, and excitation values and spectra of the compound in DMSO are given in Table 1 and Figure 3. According to literature, these fluorescence properties are characteristic for indium(III) PCS in DMSO $(29,30,38,39)$. According to these values, it has been predicted that the excitation spectra of InCIPc differ from the absorption spectra because of the loss of symmetry (34) and this demonstrates that the nuclear configuration was changed. Fluorescence spectra were observed at $725 \mathrm{~nm}$ for emission and at 713 $\mathrm{nm}$ for excitation in DMSO. The Stokes shift value $\left(\lambda_{\text {ems }}-\lambda_{\text {exc }}\right)$ of the compound was found as $12 \mathrm{~nm}$. 
Table 1: Spectral, photophysical and photochemical data for InCIPc in DMSO.

\begin{tabular}{lccccccccc}
\hline Solvent & $\begin{array}{c}\mathbf{Q} \\
\text { band } \\
\boldsymbol{\lambda}_{\max } \\
(\mathbf{n m})\end{array}$ & $\begin{array}{c}\text { Extinction } \\
\text { coefficient } \\
\left(\mathbf{c m}^{-1} / \mathbf{M}\right)\end{array}$ & loge & $\begin{array}{c}\text { Excitation } \\
\boldsymbol{\lambda}_{\text {Ex) }} \\
\mathbf{( n m )}\end{array}$ & $\begin{array}{c}\text { Emission } \\
\boldsymbol{\lambda}_{\text {Em, }} \\
(\mathbf{n m})\end{array}$ & $\begin{array}{c}\text { Stokes } \\
\text { Shift } \Delta_{\text {stokes }} \\
(\mathbf{n m})\end{array}$ & $\boldsymbol{\Phi}_{\mathbf{F}}$ & $\boldsymbol{\Phi}_{\Delta}$ & $\begin{array}{c}\boldsymbol{\Phi}_{\mathbf{d}} \\
\left(10^{-5}\right)\end{array}$ \\
\hline DMSO & 709 & 63150 & 4.80 & 713 & 725 & 12 & 0.09 & 0.76 & 2.55 \\
\hline
\end{tabular}

Ideal photosensitizers should show some fluorescent behavior in order to be able to follow them in the body. Therefore, it is important to investigate their fluorescent quantum yield $\left(\Phi_{\mathrm{F}}\right)$ characteristics for PDT applications. The $\Phi_{F}$ of InCIPc is calculated according to current literature with reference to standard $\mathrm{ZnPc}(40)$. Table 1 presents $\Phi_{\mathrm{F}}$ value of InCIPc. The $\Phi_{F}$ efficiency was calculated as 0.09 for InCIPc in DMSO. The fluorescence efficiency reduces since increasing the atomic number causes more intersystem crossing $(41,42)$. Therefore, InCIPc exhibits low values because of the heavy metal effect. InCIPc displays lower fluorescence quantum values compared to unsubstituted $\mathrm{ZnPc}$ $\left(\Phi_{\mathrm{F}}=0.20\right.$ in DMSO) and $\mathrm{Zn}(\mathrm{II})$ and $\mathrm{Mg}(\mathrm{II})$ derivatives of the same Pc (31). Owing to the enhancement of inter-system crossing by the presence of a heavy indium atom in InCIPc, $\Phi_{F}$ value is low as expected (43). This $\Phi_{F}$ value is also similar to other studied InPc compounds $(29,30)$. The fluorescent behavior of this photosensitizer is appropriate for determination and quantification of photosensitizer in PDT studies.

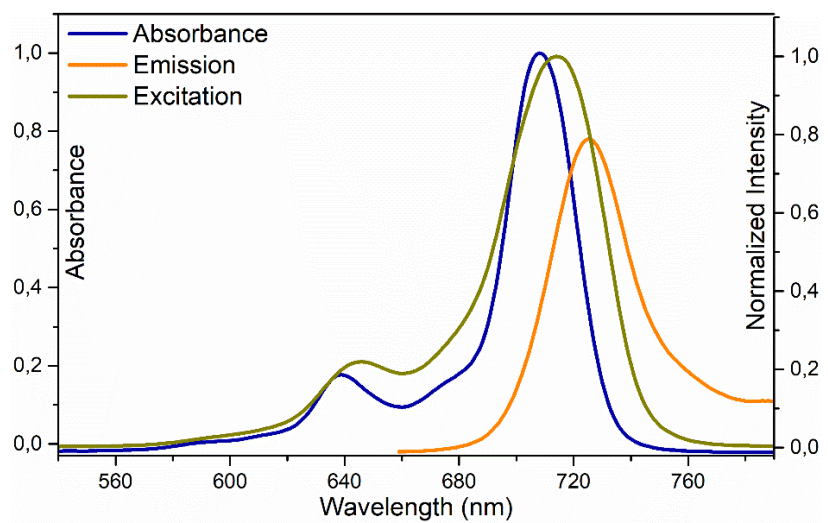

Figure 3: Fluorescent spectra of InCIPc in DMSO.

\section{Singlet oxygen production properties}

The singlet oxygen generation is an important condition used in PDT. Singlet oxygen generation is the most important behavior of photosensitizer. The singlet oxygen quantum yield $\left(\Phi_{\Delta}\right)$ which is amount of the produced singlet oxygen is the most important indicator for using of molecules as photosensitizers in PDT applications (44). The $\Phi_{\Delta}$ depends on the used solvent. A suitable solvent was biocompatible DMSO. DMSO as a solvent meets the conditions required for the photosensitizers and it is already used as a solvent in the literature for determination of the $\Phi_{\Delta}(41)$. The $\Phi_{\Delta}$ are found via 1,3-diphenylisobenzofuran (DPBF) compound, which has an absorption at $417 \mathrm{~nm}$, as a quencher. Also, the standard $\mathrm{ZnPc}$ is used as reference. The absorbance of DPBF was monitored using UV-Vis spectroscopy after each $5 \mathrm{~s}$ of light irradiation. The compound did not degrade against light irradiation, since the compound is resistant to light. The results showing the absorbance change of DPBF are given in Figure 4 and the calculated $\Phi_{\Delta}$ value is listed in Table 1 . The $\Phi_{\Delta}$ value of InCIPc is 0.76 in DMSO. While InCIPc showed higher $\Phi_{\Delta}$ value than unsubstituted $\mathrm{ZnPc}$ and $\mathrm{Mg}$ (II) derivative of the same Pc, it showed lower $\Phi_{\Delta}$ value than $\mathrm{Zn}(\mathrm{II})$ derivative of the same Pc (31). InCIPc exhibited good singlet oxygen production and it can be potential candidate as potential photosensitizer in PDT. Thanks to the enhancement of intersystem crossing by the heavy atom effect of large In(III) atom, InCIPc generates high singlet oxygen. When $\Phi_{\mathrm{F}}$ and $\Phi_{\Delta}$ are evaluated in terms of the heavy atom effect for InCIPc, decrease in $\Phi_{F}$ value accompanied by increase in $\Phi_{\Delta}$ value. InCIPc demonstrated higher $\Phi_{\Delta}$ values than Std-ZnPc which means that the substitution of 4-((2,3-dihydrobenzo[b][1,4]dioxin-2$y l)$ methoxy) groups to the macrocycle increased singlet oxygen generation. The singlet oxygen generation of this compound is similar with Pc containing different substituents on the Pc ring and In(III) metal ion in Pc cavity $(34,45,46)$. The synthesized compound has sufficient singlet oxygen generation for PDT.

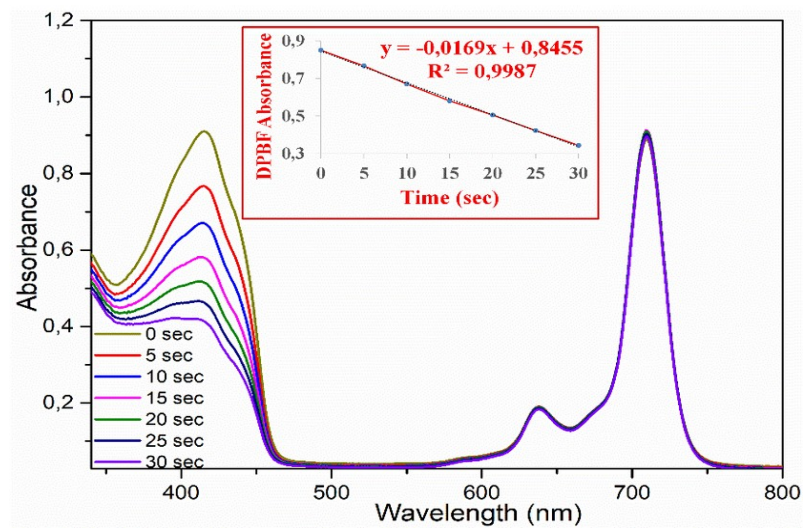

Figure 4: UV-Vis spectral changes of InCIPc during singlet oxygen production measurements in DMSO (Inset: Plot of DPBF absorbance versus time).

\section{Photodegradation properties}

Photodegradation is generally used to determine the stability of PCs, which is important in photocatalytic application reactions as well as in PDT. Photodegradation is the oxidative decomposition of the photosensitizer under light irradiation and this photodegradation is studied by quantum efficiency. The photodegradation quantum yield $\left(\Phi_{\mathrm{d}}\right)$ of 
photosensitizer play a key role in PDT. The $\Phi_{d}$ value gives the stability of the compound against the light irradiation. After exposure to light for every $5 \mathrm{~min}$ of the compound, the photodegradation studies in DMSO were performed by monitoring the decrease of the absorbance of the compound. Figure 5 presents the changes in $\mathrm{Q}$ band of the compound. The $Q$ band intensity of compound was not disturbed in DMSO under light irradiation. As we know from the literature, the $\Phi_{\mathrm{d}}$ of the stable photosensitizer are between $10^{-3}$ and $10^{-6}$ (47). The $\Phi_{d}$ value of compound presents in Table 1 and it showed about the same stability with order of $10^{-5}$ The $\Phi_{d}$ value of InCIPc in DMSO was calculated as $2.55 \times 10^{-5}$. The obtained $\Phi_{d}$ value of InCIPc are similar with $\mathrm{Zn}$ (II) and $\mathrm{Mg}$ (II) derivatives of the same Pc (31). InCIPc demonstrated lower $\Phi_{d}$ values than Std-ZnPc which means that the substitution of 4 ((2,3-dihydrobenzo[b][1,4]dioxin-2-

yl)methoxy)groups to the macrocycle increased the stability of this phthalocyanine against light irradiation. The results indicate that this compound has moderate stability to photochemical degradation. The photodegradation quantum yields $\left(\Phi_{d}\right)$ are in harmony with other $\operatorname{InPCS}(30,33,48)$ and the stability of the compound are suitable for PDT.

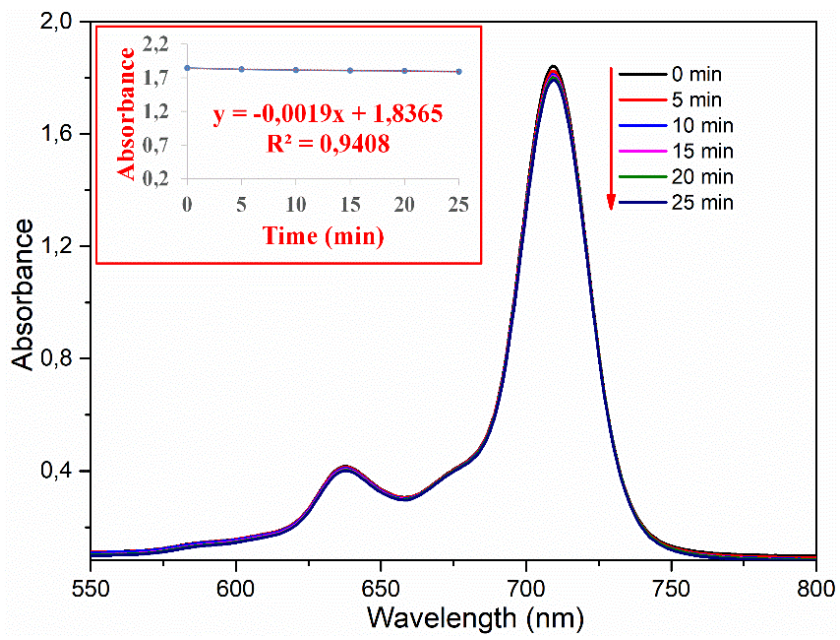

Figure 5: UV-Vis spectral change of InCIPc during photodegradation measurements in DMSO (Inset: plot of $\mathrm{Q}$ band absorbance versus time)

\section{CONCLUSIONS}

In this study, new tetra-substituted chloroindium(III) Pc bearing benzodioxane groups was synthesized and characterized by using elemental analysis, UVVis, FT-IR, ${ }^{1} \mathrm{H}$ NMR and MALDI-TOF MS techniques. At the same time, the photophysicochemical properties of the compound were researched in order to understand whether it is suitable for PDT. According to the UV-Vis measurements, we observed that this compound dissolves very well in DMSO, does not aggregate, and gives $Q$ band around $709 \mathrm{~nm}$ and $B$ band around $368 \mathrm{~nm}$. In addition, we observed that the ratio between absorption and concentration in the $\mathrm{Q}$ band changes in accordance with the Lambert-Beer law. The fluorescence spectral results show that the excitation spectrum of this compound differs from the absorption spectra and this demonstrates that the nuclear configuration was changed. The fluorescence quantum yield of the obtained compound (0.09) is lower than the unsubstituted ZnPc compound. When singlet oxygen quantum yield was examined, we observed that the compound show higher result than unsubstituted ZnPc. This situation is due to indium(III) ion being a heavy atom and increasing the transition between systems. In addition, the used benzodioxane substituted groups may have an effect on high singlet oxygen production compared to unsubstituted ZnPc compound. According to the photodegradation results, it is seen that the synthesized compound is stable to light. As a result, with this study, a candidate molecule that can be used as a potential photosensitizer in PDT applications has been reported in the literature.

Conflict of interest: The authors declare that they have no conflict of interest.

\section{REFERENCES}

1. Siegel RL, Miller KD, Jemal A. Cancer statistics, 2020. Ca-Cancer J. Clin. 2020;70(1):7-30.

2. Miller KD, Siegel RL, Lin $C C$, Mariotto $A B$, Kramer $\mathrm{JL}$, Rowland $\mathrm{JH}$, et al. Cancer treatment and survivorship statistics, 2016. Ca-Cancer J. Clin. 2016;66(4):271-89.

3. Thompson CB. Apoptosis in the pathogenesis and treatment of disease. Science. 1995;267(5203):1456-62.

4. Vanneman M, Dranoff G. Combining immunotherapy and targeted therapies in cancer treatment. Nat. Rev. Cancer. 2012;12(4):237-51.

5. Miller $A$, Hoogstraten $B$, Staquet $M$, Winkler $A$. Reporting results of cancer treatment. cancer. 1981;47(1):207-14.

6. Dougherty TJ, Gomer CJ, Henderson BW, Jori G, Kessel D, Korbelik M, et al. Photodynamic therapy. J. Natl. Cancer Inst. 1998;90(12):889-905.

7. Dolmans DE, Fukumura D, Jain RK. Photodynamic therapy for cancer. Nat. Rev. Cancer. 2003;3(5):380.

8. Li X, Kolemen S, Yoon J, Akkaya EU. Activatable photosensitizers: agents for selective photodynamic therapy. Adv Funct Mater. 2017;27(5):1604053.

9. Lukyanets EA. Phthalocyanines as photosensitizers in the photodynamic therapy of cancer. J Porphyrins Phthalocyanines. 1999;3(6):10. 
10. Ogura S-i, Tabata K, Fukushima K, Kamachi T, Okura I. Development of phthalocyanines for photodynamic therapy. J Porphyrins Phthalocyanines. 2006;10(09):1116-24.

11. Lo P-C, Rodríguez-Morgade MS, Pandey RK, Ng DK, Torres T, Dumoulin F. The unique features and promises of phthalocyanines as advanced photosensitisers for photodynamic therapy of cancer. Chem Soc Rev. 2020;49(4):1041-56.

12. Gorduk S, Altindal A. Non-peripherally tetra substituted phthalocyanines bearing carboxylic acid anchoring groups as photosensitizer for high efficient dye-sensitized solar cells. J Mol Struct. 2020;1204:127636.

13. Gregory P. Industrial applications of phthalocyanines. J Porphyrins Phthalocyanines. 2000;4(4):432-437.

14. Claessens CG, Hahn $U$, Torres $T$. Phthalocyanines: From outstanding electronic properties to emerging applications. The Chemical Record. 2008;8(2):75-97.

15. Gounden D, Nombona N, van Zyl WE. Recent advances in phthalocyanines for chemical sensor, non-linear optics (NLO) and energy storage applications. Coord Chem Rev. 2020;420:213359.

16. Karaca H. Synthesis of Novel Chalcone Substituted Metallophthalocyanines: Electrochemistry, Spectroelectrochemistry and Catalytic Oxidation of 2-mercaptoethanol. J Turk Chem Soc, Sect A: Chem. 2018;5(2):701-18.

17. Wöhrle D, Schnurpfeil G, Makarov SG, Kazarin A, Suvorova ON. Practical applications of phthalocyanines-from dyes and pigments to materials for optical, electronic and photo-electronic devices. Macroheterocycles. 2012;5(3):191-202.

18. Rosenthal I. Phthalocyanines as photodynamic sensitizers. Photochem Photobiol. 1991;53(6):859 70.

19. Liu MO, Tai C-h, Sain M-z, Hu AT, Chou F-i. Photodynamic applications of phthalocyanines. J Photochem Photobiol, A. 2004;165(1-3):131-36.

20. Kliesch $H$, Weitemeyer A, Müller $S$, Wöhrle $D$. Synthesis of phthalocyanines with one sulfonic acid, carboxylic acid, or amino group. Liebigs Annalen. 1995;1995(7):1269-73.

21. Ogunsipe A, Nyokong T. Effects of substituents and solvents on the photochemical properties of zinc phthalocyanine complexes and their protonated derivatives. J Mol Struct. 2004;689(1-2):89-97.

22. Günsel A. Comparative Studies of Photophysicochemical Properties of Non-Peripherally
Anisole/Thioanisole-Tetrasubstituted Gallium(III) Phthalocyanines Containing Oxygen/Sulfur Bridge. J Turk Chem Soc, Sect A: Chem. 2017;5(1):269-82.

23. Gorduk S. Ferulic Acid Substituted Zn(II) Phthalocyanine: Synthesis, Characterization and Investigation of Photophysical and Photochemical Properties. J Turk Chem Soc, Sect A: Chem. 2018;5(2):903-18.

24. Temizel S, Sevim AM. Synthesis and photophysical properties of A3B-type nonsymmetrically substituted anthracene-based zinc(II) phthalocyanine. J Turk Chem Soc, Sect A: Chem. 2020;7(1):107-16.

25. Güzel E. Preparation and investigation of aggregation, fluorescence and singlet oxygen generation properties of gallium and metal-free phthalocyanines. J Turk Chem Soc, Sect A: Chem. 2019;5(3):1051-60.

26. Özçeşmeci M. Aromatik azo grupları ile modifiye edilmiş, yakın-IR bölgede soğurma yapan metalsiz ve çinko(II) ftalosiyaninlerin sentezi ve karakterizasyonu. J Turk Chem Soc, Sect A: Chem.; 2015: 2(4):32-41.

27. Gorduk S, Koyun O, Avciata O, Altindal A, Avciata U. Synthesis of Peripherally Tetrasubstituted Phthalocyanines and Their Applications in Schottky Barrier Diodes. J. Chem. 2017;2017:1-9.

28. Gorduk S, Avciata O, Avciata U. Photocatalytic degradation of methylene blue under visible light irradiation by non-peripherally tetra substituted phthalocyanine- $\mathrm{TiO}_{2}$ nanocomposites. Inorg Chim Acta. 2018;471:137-47.

29. Gorduk S. Investigation of photophysicochemical properties of non-peripherally tetra-substituted metal-free, $\mathrm{Mg}(\mathrm{II}), \quad \mathrm{Zn}(\mathrm{II})$ and In(III) phthalocyanines. Polyhedron. 2020;189:114727.

30. Gorduk S. Octa-substituted metallophthalocyanines bearing (2,3-dihydrobenzo1,4-benzodioxin-2-yl) methoxy and chloro groups: Synthesis, characterization and photophysicochemical studies. J Porphyrins Phthalocyanines. 2020;24(4):548-62.

31. Demirbaş Ü, Ömeroğlu İ, Akçay HT, Durmuş $M$, Kantekin $H$. Synthesis, characterization, photophysical and photochemical properties of peripherally tetra benzodioxane substituted metalfree phthalocyanine and its zinc(II) and magnesium(II) derivatives. J Mol Struct. 2020;1223:128992.

32. Demirbaş Ü, Akyüz D, Akçay HT, Koca A, Kantekin $H$. Non-peripherally tetra substituted phthalocyanines bearing benzodioxane moieties: Synthesis, characterization and investigation of 
electrochemical and spectroelectrochemical properties. J Mol Struct. 2019;1189:234-39.

33. Uslan C, Köksoy $B$, Durmuş $M$, İşleyen ND, Öztürk Y, Çakar ZP, et al. The synthesis and investigation of photochemical, photophysical and biological properties of new lutetium, indium, and zinc phthalocyanines substituted with PEGME-2000 blocks. J. Biol. Inorg. 2019:1-20.

34. Yanık H, Aydın D, Durmuş M, Ahsen V. Peripheral and non-peripheral tetrasubstituted aluminium, gallium and indium phthalocyanines: Synthesis, photophysics and photochemistry. J Photochem Photobiol, A. 2009;206(1):18-26.

35. Nyokong T. Electronic spectral and electrochemical behavior of near infrared absorbing metallophthalocyanines. Functional Phthalocyanine Molecular Materials: Springer; 2010. p. 45-87.

36. Kadish K, Smith KM, Guilard R. The porphyrin handbook: phthalocyanines: properties and materials: Elsevier; 2000.

37. Snow AW. Phthalocyanine Aggregation. The Porphyrin Handbook: Phthalocyanines: Properties and Materials. 2000;17:129.

38. Can OS, Kaya EN, Durmuş M, Bulut M. High photosensitized singlet oxygen generating zinc(II) and indium(III) acetate phthalocyanines containing 6,8-di-tert-butyl-3-(p-oxyphenyl) coumarin groups. J Photochem Photobiol, A. 2016;317:56-67.

39. Sindelo A, Osifeko OL, Nyokong T. Synthesis, photophysicochemical and photodynamic antimicrobial chemotherapy studies of indium pyridyl phthalocyanines: Charge versus bridging atom. Inorg Chim Acta. 2018;476:68-76.

40. Ogunsipe A, Chen J-Y, Nyokong T. Photophysical and photochemical studies of zinc(II) phthalocyanine derivatives-effects of substituents and solvents. New J Chem. 2004;28(7):822-27.

41. Ogunsipe A, Maree D, Nyokong T. Solvent effects on the photochemical and fluorescence properties of zinc phthalocyanine derivatives. J Mol Struct. 2003;650(1-3):131-40.

42. Simone BCD, Mazzone $G$, Russo N, Sicilia $E$, Toscano M. Metal atom effect on the photophysical properties of $\mathrm{Mg}(\mathrm{II}), \mathrm{Zn}(\mathrm{II}), \mathrm{Cd}(\mathrm{II})$, and $\mathrm{Pd}(\mathrm{II})$ tetraphenylporphyrin complexes proposed as possible drugs in photodynamic therapy. Molecules. 2017;22(7):1093.

43. Durmuş $M$, Nyokong T. Synthesis, photophysical and photochemical properties of aryloxy tetrasubstituted gallium and indium phthalocyanine derivatives. Tetrahedron. 2007;63(6):1385-94.
44. Lovell JF, Liu TW, Chen J, Zheng G. Activatable photosensitizers for imaging and therapy. Chem Rev. 2010;110(5):2839-57.

45. Chauke $V$, Durmuş $M$, Nyokong $T$. Photochemistry, photophysics and nonlinear optical parameters of phenoxy and tert-butylphenoxy substituted indium(III) phthalocyanines. J Photochem Photobiol, A. 2007;192(2-3):179-87.

46. Ali HEA, Pişkin M, Altun S, Durmuş M, Odabaş Z. Synthesis, characterization, photophysical, and photochemical properties of novel zinc(II) and indium(III) phthalocyanines containing 2phenylphenoxy units. J Lumin. 2016;173:113-19.

47. Durmuş M. Photochemical and photophysical characterization. Photosensitizers in medicine, environment, and security: Springer; 2011. p. 135266.

48. Çapkın A, Pişkin $M$, Durmuş $M$, Bulut $M$. Spectroscopic, photophysical and photochemical properties of newly metallo-phthalocyanines containing coumarin derivative. I Mol Struct. 2020;1213:128145. 


\title{
SUPPORTING INFORMATION
}

\section{Investigation of Singlet Oxygen Production Property of Peripherally Tetra-substituted In(III)CI Phthalocyanine for Photodynamic Therapy}

\author{
Semih Gorduk*
}

Yildiz Technical University, Faculty of Arts and Science, Department of Chemistry, 34210 Istanbul, Turkey *Corresponding Author: Semih Gorduk, E-mail: sgorduk@yildiz.edu.tr, Tel: +90 2123834219.

\section{EXPERIMENTAL SECTION}

\section{Materials}

$N, N$-dimethylformamide (DMF), Dimethyl sulfoxide (DMSO), chloroform $\left(\mathrm{CHCl}_{3}\right)$, diethylether, methanol $(\mathrm{MeOH})$, tetrahydrofuran (THF), ethanol (EtOH), dichloromethane (DCM), $n$-hexane, n-pentanol, and acetone were purchased from MERCK. 4-Nitrophthalonitrile, 2-hydroxymethyl-1,4-benzodioxan, 1,8diazabicyclo[5.4.0] undec-7-ene (DBU), potassium carbonate $\left(\mathrm{K}_{2} \mathrm{CO}_{3}\right)$, anhydrous indium(III) chloride were purchased from Aldrich. All chemicals were of reagent grade. All solvents were dried and stored over molecular sieves. The progress of the reactions was monitored by thin layer chromatography (TLC).

\section{Equipments}

Melting points of compounds were determined via an electrothermal Gallenkamp device. The UV-vis measurements were made on a Shimadzu UV-2001 UV-Vis spectrophotometer. Elemental analysis studies were performed by a LECO TRUSPEC CHN 932 instrument. The IR spectra of the compounds were registered using a Thermo Fisher scientific NICOLET iS10 spectrometer (ATR sampling accessory). A Bruker Avance III $400 \mathrm{MHz}$ spectrometer was used for ${ }^{1} \mathrm{H}-\mathrm{NMR}$ analyses. MALDI-TOF mass measurements were carried out by a Bruker Microflex LT MALDI-TOF-MS. Fluorescence spectra, were registered by Varian Eclipse spectrophotometer using $1 \mathrm{~cm}$ path length cuvettes at room temperature. General electric quartz line lamp $(300 \mathrm{~W})$ was used to perform photochemical measurements. Ultraviolet and infrared radiations were filtered using A $600 \mathrm{~nm}$ glass cut off filter (Schott) and a water filter, respectively. An extra interference filter (Intor, 670 or $700 \mathrm{~nm}$ with a band width of $40 \mathrm{~nm}$ ) was placed through the light path before the sample. A POWER MAX5100 (Molelectron detector incorporated) power meter was utilized to determine light intensities.

\section{Photophysical and Photochemical Measurements}

Fluorescence quantum yield $\left(\Phi_{F}\right)$ measurements

The $\Phi_{\mathrm{F}}$ values were calculated by the comparative method (Eq. 1) [1, 2] using unsubstituted ZnPc as the reference. The $\Phi_{F}$ value of unsubstituted $\mathrm{ZnPc}$ is 0.20 in DMSO $[3,4]$. Both the synthesized Pcs and the standard were excited at convenient wavelength.

$$
\Phi_{F}=\Phi_{F}(S t d) \frac{F \times A_{S t d} \times n^{2}}{F_{S t d} \times A \times n_{S t d}^{2}}
$$

In Eq. 1, F and $F_{\text {std }}$ are the areas under the fluorescence emission curves of the synthesized Pc and standard unsubstituted $\mathrm{ZnPc}$, respectively. $\mathrm{A}$ and $\mathrm{A}_{\text {std }}$ are the absorbances of the synthesized $\mathrm{Pc}$ and standard unsubstituted $\mathrm{ZnPc}$ at the excitation wavelengths, respectively. The $\eta$ and $\eta_{\text {std }}$ are the refractive indices of used solvents for the synthesized Pc and standard unsubstituted ZnPc, respectively.

\section{Singlet oxygen quantum yield $\left(\Phi_{\Delta}\right)$ measurements}

The $\Phi_{\Delta}$ measurements were performed using the experimental setup described in previous studies [4, 5] with standard unsubstituted ZnPc (in DMSO) as the reference. $2 \mathrm{~mL}$ of the synthesized Pc solution $\left(C=1.0 \times 10^{-5} \mathrm{M}\right)$ containing the singlet oxygen scavenger was irradiated in the Q-band region using the photoirradiation setup described in the literature. The $\Phi_{\Delta}$ values were calculated via the relative method with DPBF (singlet oxygen chemical scavenger) in DMSO using Eq. 2.

$$
\Phi_{\Delta}=\Phi_{\Delta}^{\mathrm{Std}} \frac{\mathrm{R} \cdot \mathrm{I}_{\mathrm{abs}}^{\mathrm{Std}}}{\mathrm{R}^{\mathrm{Std}} \cdot \text { Iabs }}
$$


$\Phi_{\Delta}$ std is $\Phi_{\Delta}$ for the standard unsubstituted $\mathrm{ZnPc}$ ( $\Phi_{\Delta}^{\text {std }}=0.67$ in DMSO) $[1,6] . R$ and $R_{\text {std }}$ are DPBF photobleaching rates in the presence of the synthesized Pc and standard unsubstituted ZnPc, respectively. $\mathrm{l}_{\text {abs }}$ and $\mathrm{l}_{\mathrm{abs}}^{\text {std }}$ are the rates of light absorption by the synthesized Pc and standard unsubstituted $\mathrm{ZnPC}$, respectively. The concentration of DPBF was lowered to $\sim 3 \times 10^{-5} \mathrm{M}$ to avoid chain reactions formed by DPBF in the presence of singlet oxygen [7]. Solutions of the photosensitizer including DPBF were prepared in the dark environment and irradiated in the Q-band region using the described setup in the measurements part. Degradation of DPBF at $417 \mathrm{~nm}$ was monitored. The used light intensity in $\Phi_{\Delta}$ value measurements is $7.05 \times 10^{15}$ photons. $\mathrm{s}^{-1} \cdot \mathrm{cm}^{-2}$

Photodegradation quantum yield $\left(\Phi_{d}\right)$ measurements

The $\Phi_{d}$ measurements were performed by the experimental setup described in previous studies [8]. $\boldsymbol{\Phi}_{d}$ values of the synthesized Pcs were calculated via Eq. 3.

$$
\Phi_{d}=\frac{\left(C_{0}-C_{t}\right) \times V \times N_{A}}{I_{\mathrm{abs}} \times S \times t}
$$

In Equation 3, $\mathrm{S}$ is the irradiated cell area, $\mathrm{t}$ is the irradiation time, $\mathrm{C}_{0}$ and $\mathrm{C}_{\mathrm{t}}$ are the sample concentration before and after irradiation, respectively, $\mathrm{V}$ is the used volume of solution in measurement, $\mathrm{N}_{\mathrm{A}}$ is the Avogadro's constant and $\mathrm{l}_{\text {abs }}$ is the overlap integral of the radiation source light intensity and the absorption of the synthesized Pc. The used light intensity in $\Phi_{\mathrm{d}}$ value measurements is $2.20 \times 10^{16}$ photons $\mathrm{s}^{-1} . \mathrm{cm}^{-2}$.

\section{Synthesis of $2(3), 9(10), 16(17), 23(24)$-tetrakis- $\{(2,3$-dihydrobenzo[b][1,4]dioxin-2-yl)methoxy) phthalociyaninato chloro indium(III) (InCIPc)}

The compound was synthesized according to given procedure in our previous works [9]. The mixture of 4((2,3-dihydrobenzo[b][1,4]dioxin-2-yl)methoxy)phthalonitrile compound $(0.2 \mathrm{~g}, 0.69 \mathrm{mmol})$, n-pentanol (4 $\mathrm{mL}$ ), 1,8-diazabicyclo[4.5.0]undec-7-ene (DBU) (5 drops), equivalent amounts of anhydrous $\mathrm{InCl}_{3}$ heated to $160^{\circ} \mathrm{C}$ and stirred for $24 \mathrm{~h}$ at this temperature under $\mathrm{N}_{2}$ atmosphere. Then cooling to room temperature, the reaction mixture was precipitated by the addition of $\mathrm{n}$-hexane and filtered off. After washing with hot $\mathrm{MeOH}$ and hot EtOH, the product was purified with column chromatography by using silica gel and THF/MeOH solvent system. Solvent system for column chromatography was THF/MeOH (100:6).

\section{REFERENCES}

1. S. Fery-Forgues, D. Lavabre, Are fluorescence quantum yields so tricky to measure? A demonstration using familiar stationery products, J. Chem. Educ. 76(9) (1999) 1260.

2. M.D. Maree, T. Nyokong, K. Suhling, D. Phillips, Effects of axial ligands on the photophysical properties of silicon octaphenoxyphthalocyanine, J. Porphyrins Phthalocyanines 6(06) (2002) 373-376.

3. A. Ogunsipe, J.-Y. Chen, T. Nyokong, Photophysical and photochemical studies of zinc(II) phthalocyanine derivatives-effects of substituents and solvents, New J. Chem. 28(7) (2004) 822-827.

4. I. Gürol, M. Durmuş, V. Ahsen, T. Nyokong, Synthesis, photophysical and photochemical properties of substituted zinc phthalocyanines, Dalton Trans. (34) (2007) 3782-3791.

5. A. Ogunsipe, T. Nyokong, Effects of substituents and solvents on the photochemical properties of zinc phthalocyanine complexes and their protonated derivatives, J. Mol. Struct. 689(1-2) (2004) 89-97.

6. A. Ogunsipe, D. Maree, T. Nyokong, Solvent effects on the photochemical and fluorescence properties of zinc phthalocyanine derivatives, J. Mol. Struct. 650(1-3) (2003) 131-140.

7. W. Spiller, H. Kliesch, D. Wöhrle, S. Hackbarth, B. Röder, G. Schnurpfeil, Singlet oxygen quantum yields of different photosensitizers in polar solvents and micellar solutions, J. Porphyrins Phthalocyanines 2(2) (1998) 145-158.

8. A. Ogunsipe, T. Nyokong, Photophysical and photochemical studies of sulphonated non-transition metal phthalocyanines in aqueous and non-aqueous media, J. Photochem. Photobiol., A 173(2) (2005) 211-220.

9. S. Gorduk, O. Koyun, O. Avciata, A. Altindal, U. Avciata, Synthesis of Peripherally Tetrasubstituted Phthalocyanines and Their Applications in Schottky Barrier Diodes. Journal of Chemistry. 2017 (2017) 1-9. 